\title{
The association between social support and antenatal depressive and anxiety symptoms among Australian women
}

\author{
Asres Bedaso ${ }^{1,2^{*}}$, Jon Adams ${ }^{2}$, Wenbo Peng ${ }^{2}$ and David Sibbritt ${ }^{2}$
}

\begin{abstract}
Background: Antenatal depression and antenatal anxiety adversely affect several obstetric and foetal outcomes, and increase the rate of postnatal mental illness. Thus, to tackle these challenges the need for social support during pregnancy is vital. However, an extensive literature search failed to show a published study on the relationship between domains of social support and antenatal depressive, as well as antenatal anxiety symptoms in Australia. This study examined the association between domains of social support and antenatal depressive and anxiety symptoms among Australian women.

Methods: The current study used data obtained from the 1973-78 cohort of the Australian Longitudinal Study on Women's Health (ALSWH), focusing upon women who reported being pregnant $(n=493)$. Depression and anxiety were assessed using the 10 item Center for Epidemiological Studies Depression (CES-D-10) scale, and the 9-item Goldberg Anxiety and Depression scale (GADS) respectively. The 19 item-Medical Outcomes Study Social Support index (MOSS) was used to assess social support. A logistic regression model was used to examine the associations between domains of social support and antenatal depressive and anxiety symptoms after adjusting for potential confounders.

Result: The current study found 24.7 and $20.9 \%$ of pregnant women screened positive for depressive and anxiety symptoms respectively. After adjusting for potential confounders, our study found that the odds of antenatal depressive symptoms was about four and threefold higher among pregnant women who reported low emotional/informational support ( $\mathrm{AOR}=4.75 ; 95 \% \mathrm{Cl}: 1.45,15.66 ; p=0.010$ ) and low social support (overall support) $(\mathrm{AOR}=3.26$; $95 \%$ Cl: $1.05,10.10, p=0.040$ ) respectively compared with their counterpart. In addition, the odds of antenatal anxiety symptoms was seven times higher among pregnant women who reported low affectionate support/positive social interaction $(\mathrm{AOR}=7.43 ; 95 \% \mathrm{Cl}: 1.75,31.55 ; p=0.006)$.
\end{abstract}

Conclusion: A considerable proportion of pregnant Australian women had depressive symptoms and/or anxiety symptoms, which poses serious health concerns. Low emotional/informational support and low affectionate support/ positive social interaction have a significant association with antenatal depressive and anxiety symptoms respectively. As such, targeted screening of expectant women for social support is essential.

\footnotetext{
*Correspondence: asresbedaso@gmail.com; AsresBedaso.Tilahune@student.

uts.edu.au

${ }^{2}$ Australian Centre for Public and Population Health Research, School

of Public Health, Faculty of Health, University of Technology Sydney,

Ultimo, NSW, Australia

Full list of author information is available at the end of the article
} original author(s) and the source, provide a link to the Creative Commons licence, and indicate if changes were made. The images or other third party material in this article are included in the article's Creative Commons licence, unless indicated otherwise in a credit line to the material. If material is not included in the article's Creative Commons licence and your intended use is not permitted by statutory regulation or exceeds the permitted use, you will need to obtain permission directly from the copyright holder. To view a copy of this licence, visit http://creativecommons.org/licenses/by/4.0/. The Creative Commons Public Domain Dedication waiver (http://creativeco mmons.org/publicdomain/zero/1.0/) applies to the data made available in this article, unless otherwise stated in a credit line to the data. 
Keywords: Depressive symptoms, Anxiety symptoms, Social support, Emotional support, Affectionate support, Tangible support, Women, Pregnancy

\section{Background}

Pregnancy is a period that brings physiological and psychosocial changes in women, which increases the risk for the occurrence of mental illness [1,2]. Depression and anxiety are among the most common mental illness occurring during pregnancy $[3,4]$.

Depression is characterized by symptoms of depressed mood, or loss of interest, low self-esteem, feelings of worthlessness, loss of appetite, feelings of fatigue, and poor concentration [5]. A previous meta-analysis conducted in developed countries reported a 7.4, 12.8 and $12 \%$ pooled prevalence of antenatal depression during the 1st, 2nd and 3rd trimester, respectively [6]. Also, a $25.3 \%$ pooled prevalence of antenatal depression was reported by a meta-analysis conducted in low and middle-income countries (LMICs) [7]. An estimated prevalence of antenatal depression reported by studies conducted in Australian ranges, 6-6.2\% [8, 9], 7\% [10] and 16.9\% [11].

Antenatal anxiety is defined as excess concerns about the pregnancy, childbirth, health of the infant and future parenting roles [12]. Based on a report of global level meta-analysis the pooled prevalence of antenatal anxiety estimated a $34.4 \%$ pooled prevalence in LMICs and $19.4 \%$ in high-income countries [13]. Studies conducted in Australia revealed that the prevalence of antenatal anxiety ranges between 14 and 59\% [14-19].

The risk factors for antenatal anxiety include previous pregnancy loss [20-22], stress [23], abuse during pregnancy [23-25], history of mental illness [23, 25-27], smoking/substance abuse [21, 23, 28, 29], drinking alcohol [28], antenatal depression, food insecurity, unplanned pregnancy [30], low social support, and poor quality relationship with a partner [31]. The risk factors for antenatal depression include anxiety, low social support, major life events, low income, history of abuse [8,11,32], domestic violence [32], unplanned pregnancy, history of any mental illness, and stress [33, 34].

Antenatal depression and anxiety adversely affect several obstetric and foetal outcomes and cause an increased rate of pregnancy complications and postnatal mental health problems [35-38]. Untreated antenatal anxiety and depression may lead to postnatal depression for the mother which may also result in an impaired interaction with her infant [39-41]. Thus, to tackle these challenges the need for social support during pregnancy is vital [42].

Social support is defined as the provision of financial, instrumental, emotional, and psychological support for somebody by a social network of family members, friends, and community members [43]. It strengthens social relationships and promotes health and well-being for a successful pregnancy [44]. However, the relationship between the specific domains of social support and antenatal depression, as well as antenatal anxiety symptoms remains understudied in Australia and globally. In addition, within the available evidence, there is a knowledge gap and reported inconsistencies regarding the association between specific domains of social support and mental health problems among pregnant women. Understanding the relationship between specific domains of social support and antenatal depression, as well as antenatal anxiety can assist in the process of establishing a specific type of community-based social support program to enhance the mental wellbeing of pregnant women.

Therefore, to address the abovementioned gaps in the current literature this study examined the association between domains of social support and antenatal anxiety and antenatal depressive symptoms amongst Australian women.

\section{Methods \\ Study design, population and sampling}

The current study employed a community based crosssectional study design and reported per the guideline of the STROBE checklist (Additional file 1). This study analyses data from the 1973-78 cohort of the Australian Longitudinal Study on Women's Health (ALSWH) $[45,46]$. ALSWH is a community-based longitudinal study focusing on the health and well-being of Australian women. Over 40,000 women were recruited to participate in 1996 (baseline) in three cohorts (1973-78, 1946-51 and 192126). Participants were selected randomly via the national health insurance database and completed mailed surveys every 3 years on average. From the 8010 women who completed Survey 6 of the 1973-78 cohort in 2012, those who reported being pregnant $(n=493)$ (age between 34 and 39 years) were included in the current analyses [47]. Additional Information about the ALSWH can be found on the project website (www.alswh.org.au) and elsewhere [46].

\section{Outcome and exposure variables}

Antenatal depressive and anxiety symptoms were the outcome variables. The depressive symptom was assessed using the 10-item Center for Epidemiological Studies Depression (CES-D-10, possible range 0-30) scale. 
A cut-off point $\geq 10$ out of 30 indicates the presence of depressive symptoms [48]. It has been used to examine depressive symptoms during pregnancy with good reliability $(\alpha=0.79)$ and validity (sensitivity: $97 \%$; specificity: 84\%) [49-53]. The anxiety symptoms were assessed using the anxiety subscale of the Goldberg Anxiety and Depression scale (GADS) (yes/no, a possible range 0-9). GADS anxiety score of $\geq 6$, indicates the presence of anxiety symptoms and has good reliability $(\alpha=0.77)$ [54] and validity (sensitivity: $83.1 \%$, specificity: $81.8 \%$ ). The GADS has been used with pregnant women in Australia [55].

The exposure variable for the current study was social support. The Medical Outcomes Study Social Support index (MOSS) was used to examine the functional support provided, with good reliability $(\alpha=0.97)$ and validity $[56,57]$ and used among Australian women [58]. MOSS has an overall index of 19 items and four functional support subscales: emotional/informational support (8 items), tangible support (4 items), and affectionate/ positive social interaction ( 7 items). Emotional/informational support is the expression of positive affect, being empathic, and providing advice or information which can provide a solution to a problem. Affectionate support/ positive social interaction is the expression of love, affection and availability of others to share entertaining activities with an individual. Tangible/instrumental support is the provision of material or financial assistance. Each of the 19 items has a 5-point Likert response (ranging from: 'none of the time' $=1$ to 'all of the time' $=5$ ) assessing the availability of support. Overall score and each domain of social support were categorized into high ("all of the time" and "most of the time") and low ("a little of the time/none" and "some of the time") social support [56].

\section{Potential confounders and instruments used}

Our study adjusted the potential confounders identified from previous studies and available in our dataset. The confounders were categorized into socio-demographic, behavioural and psychological, and obstetric factors. The socio-demographic confounders included; age, residence, marital status, highest educational qualification, and able to manage on available income $[8,11,32]$. Behavioural and psychological factors included; ever being in a violent relationship with a partner (yes/no) [31], substance use (current tobacco smoking, alcohol use, and ever used illicit drug) [21, 23, 28, 29], history of mental illness (history of depression in the past 3 years, and history of anxiety in the past three years) [33,34], stress [23], and optimism. Finally, the obstetric confounding factors included; gestational age (months), GP use in the last 12 months, pre-term history [33, 34], BMI [30], and general health condition from their own perspective.
Study participants were requested to specify their marital status as either "married," "never married," "de facto," "separated," "divorced," or "widowed." For the current analysis, groups were re-categorized into either "partnered" (married or de facto) or "non-partnered" (single, divorced, separated, or widowed). Postcode of residence was used to categorise respondents as living in either "major cities of Australia", "inner regional Australia", "outer regional Australia" or "remote or very remote Australia" [59]. Income stress was measured via how respondents reported ability to manage on available income, with response options: "impossible", "difficult all of the time", "difficult some of the time", "not too bad", or "easy". For the purposes of analyses, these options were collapsed into 2 categories, "impossible or difficult all or some of the time" and "not too bad or easy".

The level of stress in the last 12 months among study participants was assessed using the Perceived Stress Questionnaire, which has been developed and validated for the ALSWH study [60]. The tool examined the level of perceived stress in specific areas of life, including study, relationships and own health. An overall mean stress score was determined, which ranges from 0 (no stress) to 4 (extreme stress). The Perceived Stress Questionnaire has good internal reliability $(\alpha=0.75)[61,62]$. Also, the Life-Orientation Test-Revised (LOT-R) was used to examine optimism (a scale of $0-24$ ).

The consumption of alcohol among study participants was assessed using the National Health and Medical Research Council (NHMRC) guidelines and categorized as: low-risk drinker; non-drinker; rarely drinks; risky/ high-risk drinker [63]. Due to the small number of responses, the consumption of alcohol was then re-categorized as being either "low risk-drinker" (non-drinker low-risk drinker/rarely drinks) or a "high-risk drinker" (risky/high-risk drinker) of alcohol. Also, based on their response to a question asking their current status of cigarette smoking, participants were categorized as being either a "non-smoker" or a "current smoker" of cigarettes. Study participants were asked if they used any of the following illicit drugs in the past 12-month; Marijuana; Amphetamines; LSD; Hallucinogens; Tranquillizers; Cocaine; Ecstasy/designer drugs; Inhalants; Heroin; Barbiturates; and Steroids. Based on their responses, the women were classified as being either a "non-user" or a "user" of an illicit drug.

Pregnancy body mass index (BMI) was assessed using self-reported weight during pregnancy $(\mathrm{kg}) /$ height $(\mathrm{m})$ ${ }^{2}$, and classified according to the WHO's classification, underweight $\left(<18.5 \mathrm{~kg} / \mathrm{m}^{2}\right)$, normal weight (BMI 18.5$\left.24.99 \mathrm{~kg} / \mathrm{m}^{2}\right)$, overweight (BMI of $\left.25-29.9 \mathrm{~kg} / \mathrm{m}^{2}\right)$ and obese $\left(\mathrm{BMI} \geq 30 \mathrm{~kg} / \mathrm{m}^{2}\right)[64]$. 


\section{Data analysis}

Data were analysed using SPSS version 22. Chi-square tests and independent sample t-test analysis were performed to test for crude associations between the outcome variables (antenatal anxiety and depressive symptoms) and the confounding variables. Exposure variables include low emotional/instrumental support, low affectionate support/positive social interaction and low tangible support. The prevalence of antenatal anxiety and antenatal depressive symptoms was calculated for each of the independent variables.

During the bivariate analyses, variables with $p \leq 0.25$ were entered into a multiple logistic regression model and adjusted for confounder. In the final model, the strength of association between the outcome variables and domains of social support was measured by adjusted odds ratios (AOR) with corresponding 95\% confidence intervals. The significance level was set at $p<0.05$. The final model was assessed using the Hosmer and Lemeshow goodness of fit test [65].

A sensitivity analysis was conducted to estimate the E-values to assess the effect of unmeasured confounding [66]. The E-value is the minimum strength of association on the odds ratio estimate that an unmeasured confounder possibly will require to have with both the exposure and outcome to negate the reported associations based on measured confounders $[67,68]$.

\section{Result}

\section{Demographic characteristics of participants}

Table 1 describes the demographic characteristics of the study participants according to their risk of depression and anxiety as examined by the CESD-10 and GAD scale respectively. The prevalence of antenatal depression and anxiety in the current study was found to be $24.7 \%$ (95\% CI: $21.2,28.9)$, and $20.9 \%$ (95\% CI: 17.5, 24.8) respectively. Also, $13.6 \%$ of pregnant women had comorbid depressive and anxiety symptoms. Of the total study participants, 11.8 and $6.5 \%$ had a history of depression and anxiety in the past 3 years respectively.

The mean $( \pm S D)$ age of the participants was 36.3 (standard deviation $[\mathrm{SD}]=1.42$ ) and the majority of participants (95.1\%) were married/De facto, while (65\%) achieved a university degree. The majority of women $(61.1 \%)$ lived in major cities and there was a significant mean age difference between pregnant women with and without depressive symptoms and it was higher among pregnant women with depressive symptoms $(p=0.029)$. There was a significant relationship between the marital situation and depression

Table 1 The associations between sociodemographic characteristics of pregnant women and antenatal depression and anxiety $(n=493)$

\begin{tabular}{|c|c|c|c|c|c|c|c|c|}
\hline \multirow{3}{*}{ Demographic characteristics } & \multicolumn{3}{|c|}{ Antenatal Depression } & \multirow[t]{3}{*}{$p$-value } & \multicolumn{3}{|c|}{ Antenatal Anxiety } & \multirow{3}{*}{ p-value } \\
\hline & $\begin{array}{l}\text { No } \\
(n=365)\end{array}$ & $\begin{array}{l}\text { Yes } \\
(n=122)\end{array}$ & $\begin{array}{l}\text { Total } \\
(n=493)\end{array}$ & & $\begin{array}{l}\text { No } \\
(n=390)\end{array}$ & $\begin{array}{l}\text { Yes } \\
(n=103)\end{array}$ & $\begin{array}{l}\text { Total } \\
(n=49)\end{array}$ & \\
\hline & n (\%) & n (\%) & n (\%) & & n (\%) & n (\%) & n (\%) & \\
\hline \multicolumn{9}{|l|}{ Residence } \\
\hline Major cities & $220(63.8)$ & $64(54.7)$ & 284(61.4) & 0.210 & $230(62.3)$ & $56(56.6)$ & $286(61.1)$ & 0.514 \\
\hline Inner regional & $69(20)$ & $31(26.5)$ & $100(21.6)$ & & $80(21.7)$ & $23(23.2)$ & 103(22) & \\
\hline Outer regional/remote/very remote & $56(16.2)$ & $22(18.8)$ & $78(17)$ & & $59(16)$ & $20(20.2)$ & $79(16.9)$ & \\
\hline \multicolumn{9}{|l|}{ Highest qualification } \\
\hline University & $246(67.4)$ & $71(58.7)$ & $317(63.9)$ & 0.272 & $257(66.2)$ & $62(60.2)$ & $319(65)$ & 0.517 \\
\hline Certificate/diploma or trade/apprenticeship & $80(21.9)$ & $31(25.6)$ & $111(22.4)$ & & $85(21.9)$ & $27(26.2)$ & $112(22.8)$ & \\
\hline School only & $39(10.7)$ & $29(15.7)$ & $68(13.7)$ & & $46(11.9)$ & $14(13.6)$ & $60(12.2)$ & \\
\hline \multicolumn{9}{|l|}{ Marital status } \\
\hline Partnered & $352(96.4)$ & $111(91)$ & $463(95)$ & 0.016 & $370(95.1)$ & $98(95.1)$ & 468(95.1) & 0.990 \\
\hline non-partnered & $13(3.6)$ & $11(9)$ & $12(5)$ & & $19(4.9)$ & $5(4.9)$ & $24(4.9)$ & \\
\hline \multicolumn{9}{|l|}{ Able to manage on income available } \\
\hline Impossible/Difficult all of the time & $18(4.9)$ & $25(20.7)$ & $43(8.8)$ & $<0.001$ & $23(5.9)$ & $20(19.6)$ & $43(8.8)$ & $<0.001$ \\
\hline Difficult some of the time & $82(22.5)$ & $32(26.4)$ & $114(23.5)$ & & $89(22.9)$ & $29(28.4)$ & 118(24) & \\
\hline \multirow[t]{2}{*}{ Not too bad/lt is easy } & $265(72.6)$ & $64(52.9)$ & $329(67.7)$ & & $277(71.2)$ & $53(52)$ & $330(67.2)$ & \\
\hline & Mean (SD) & Mean (SD) & & p-value & Mean (SD) & Mean (SD) & & $p$-value \\
\hline Age & 35.78(1.39) & $36.1(1.45)$ & $35.8( \pm 1.40)$ & 0.029 & $35.86(1.42)$ & 35.85 (1.39) & $35.8( \pm 1.4)$ & 0.977 \\
\hline
\end{tabular}


status of participants, those with depressive symptoms were more likely to be non-partnered $(p<0.016)$.

\section{Behavioural, psychological and obstetric characteristics of participants}

The behavioural, psychological, and obstetric characteristics of the study participants are presented in Table 2. The majority of the women (42.1\%) were in the last trimester of their pregnancy, while 37.5 and 20.5\% were in the second and first trimester respectively. There was a significant association between women's use of GP in the last 12-month and antenatal depressive $(p=0.025)$ and antenatal anxiety symptoms $(p<0.001)$. From the total study participants, $38.4 \%$ of them reported $\geq 5$ times General Practitioner (GP) use in the last 12 months. In terms of birth history, 14.3, 7 and $4.7 \%$ of participants had Cesarean section $(\mathrm{C} / \mathrm{S})$, preterm and low birth weight history respectively. Based on WHO BMI classification, most pregnant women (54.4\%) had normal weight and $2.7 \%$ were underweight. Also, there was a significant association between BMI and antenatal depressive symptoms among study participants, and those with depressive symptoms were more likely to be obese $(p=0.034)$.

The majority of participants (71.4\%) reported excellent/very good general health condition. Participant's general health condition status was significantly associated with their status of antenatal depressive $(p<0.001)$ and antenatal anxiety symptoms $(\mathrm{p}<0.001)$. Participants with depressive as well as anxiety symptoms were more likely to have a fair/poor general health condition $(p<0.001)$.

Of the total study participants, $11 \%$ ever had a violent relationship with a partner and ever being in a violent relationship with a partner was significantly associated with antenatal anxiety $(p<0.001)$ and antenatal depressive symptoms $(\mathrm{p}<0.001)$. Participants with depressive symptoms were more likely to have less optimism score $(p<0.001)$, and higher mean stress level $(\mathrm{p}<0.001)$. Likewise, those with anxiety symptoms were more likely to have a higher mean stress level $(p<0.001)$ and less optimism score $(\mathrm{p}<0.001)$. Compared to non-depressed participants, a higher proportion of women with depressive symptoms reported current anxiety symptoms $(\mathrm{p}<0.001)$, a personal history of anxiety $(\mathrm{p}<0.001)$, and depression in the past 3 years $(p<0.001)$. Also, compared to non-anxious participants, a higher percentage of pregnant women with anxiety symptoms reported current depressive symptoms $(\mathrm{p}<0.001)$. Participants with current anxiety symptoms were more likely to have a personal history of depression $(\mathrm{p}<0.001)$ and antenatal anxiety $(\mathrm{p}<0.001)$ in the past 3 years.

\section{Associations between social support and depressive symptoms during pregnancy}

The relationship between depressive symptoms and social support during pregnancy is presented in Table 3. After adjusting for potential confounders, the multiple logistic regression model found that the odds of antenatal depressive symptoms was fourfold higher among pregnant women who reported low emotional/ informational support $(\mathrm{AOR}=4.75 ; 95 \%$ CI: 1.45 , $15.66 ; p=0.010)$ compared with pregnant women who reported high emotional/informational support. Also, pregnant women who reported low social support (overall support) were three times more likely to be depressed (AOR: 3.26, 95\% CI: 1.05, 10.10, $p=0.040$ ) compared with their counterparts.

\section{Associations between social support and anxiety symptoms during pregnancy}

Table 4 shows the association between anxiety symptoms and low social support during pregnancy. After adjusting for potential confounders, the multiple logistic regression model found that the odds of antenatal anxiety symptoms was seven times higher among pregnant women who reported low affectionate support/positive social interaction $(\mathrm{AOR}=7.43 ; 95 \% \mathrm{CI}$ : $1.75,31.55 ; p=0.006$ ) compared with pregnant women who reported high affectionate support/positive social interaction.

\section{Sensitivity analysis}

We ran a sensitivity analysis to calculate the E-values to observe the effect of unmeasured confounders in the final adjusted model. It has been suggested that for measures of dichotomous outcomes, the respective E-values for point estimates and confidence interval can be obtained using the Odds ratio (OR) (outcome prevalence $>15 \%$ ) and its corresponding $95 \% \mathrm{CI}$ in the online $\mathrm{E}$-value formula $[67,68]$. Based on this assumption, statistical evidence from our E-values suggested that the odds ratio of the relationship between an unmeasured confounder and (i) low emotional support and antenatal depressive symptoms, (ii) low social support (overall support) and antenatal depressive symptoms and (iii) low affectionate support and antenatal anxiety symptoms would need to be at least 3.78, 3.01 (Additional file 2) and 4.89 (Additional file 3) respectively, for each association to negate the associations we found in the current study.

\section{Discussion}

This study revealed several important findings in relation to the prevalence rate of anxiety and depression, as well as the relationship between low social support 
Table 2 The association between behavioral, psychological and obstetric characteristics of pregnant women and antenatal depression and anxiety $(n=493)$

\begin{tabular}{|c|c|c|c|c|c|c|c|c|}
\hline \multirow{3}{*}{ Variables } & \multicolumn{2}{|c|}{ Antenatal Depression } & \multirow{3}{*}{$\begin{array}{l}\begin{array}{l}\text { Total } \\
(n=493)\end{array} \\
n(\%)\end{array}$} & \multirow[t]{3}{*}{$\mathrm{p}$-value } & \multicolumn{2}{|c|}{ Antenatal Anxiety } & \multirow{3}{*}{$\begin{array}{l}\begin{array}{l}\text { Total } \\
(n=493)\end{array} \\
n(\%)\end{array}$} & \multirow[t]{3}{*}{ p-value } \\
\hline & $\begin{array}{l}\text { No } \\
(n=365)\end{array}$ & $\begin{array}{l}\text { Yes } \\
(n=122)\end{array}$ & & & \multirow{2}{*}{$\begin{array}{l}\text { No } \\
(n=390) \\
n(\%)\end{array}$} & \multirow{2}{*}{$\begin{array}{l}\text { Yes } \\
(n=103) \\
n(\%)\end{array}$} & & \\
\hline & n (\%) & n (\%) & & & & & & \\
\hline \multicolumn{9}{|l|}{ Pregnancy months } \\
\hline$<3$ month & $74(20.3)$ & $25(20.5)$ & $99(20.3)$ & 0.950 & $81(20.8)$ & $20(19.4)$ & $101(20.4)$ & 0.746 \\
\hline $3-6$ month & $140(38.4)$ & $45(36.9)$ & 185(38) & & $143(36.7)$ & $42(40.8)$ & $185(37.5)$ & \\
\hline$>6$ month & $151(41.4)$ & $52(42.6)$ & 203(41.7) & & $166(42.6)$ & $42(39.8)$ & $208(42.1)$ & \\
\hline \multicolumn{9}{|l|}{ GP use in the last 12 month } \\
\hline $1-2$ times & $108(29.7)$ & $22(18)$ & $130(26.7)$ & 0.025 & $116(29.8)$ & $16(15.5)$ & 132(26.8) & $<0.001$ \\
\hline 3-4 times & $125(34.3)$ & $43(35)$ & 168(34.6) & & $137(35.2)$ & $32(31.1)$ & 169(34.3) & \\
\hline$\geq 5$ times & $131(36)$ & $57(46.7)$ & 188(38.7) & & $136(35)$ & $55(53.4)$ & 191(38.9) & \\
\hline \multicolumn{9}{|l|}{ History of C/S } \\
\hline Yes & $49(13.5)$ & $18(14.9)$ & 67(13.9) & 0.710 & $55(14.2)$ & $15(14.6)$ & $70(14.3)$ & 0.935 \\
\hline No & $313(86.5)$ & $103(21.3)$ & $416(86.1)$ & & $331(85.8)$ & $88(85.4)$ & 419(85.7) & \\
\hline \multicolumn{9}{|l|}{ Preterm history } \\
\hline Yes & $24(6.7)$ & $10(8.3)$ & $34(7)$ & 0.553 & $30(7.8)$ & $4(3.9)$ & $34(7)$ & 0.173 \\
\hline No & $336(93.3)$ & $111(91.7)$ & $447(93)$ & & $355(92.2)$ & $98(96.1)$ & 453(93) & \\
\hline \multicolumn{9}{|l|}{ Low birth weight history } \\
\hline Yes & $16(4.4)$ & $7(5.7)$ & $23(4.8)$ & 0.558 & $19(4.9)$ & $4(3.9)$ & $23(4.7)$ & 0.650 \\
\hline No & $345(95.6)$ & $115(94.3)$ & $460(95.2)$ & & $367(95.1)$ & $99(96.1)$ & 466(95.3) & \\
\hline \multicolumn{9}{|l|}{ Body Mass Index (BMI) } \\
\hline Acceptable/Underweight $(<25)$ & $218(60.7)$ & $58(47.5)$ & $276(57.4)$ & 0.034 & $224(58.2)$ & $54(52.9)$ & $278(57.1)$ & 0.603 \\
\hline Overweight (25-30) & $87(24.2)$ & $37(30.3)$ & 124(25.8) & & $98(25.5)$ & $28(27.5)$ & 126(25.9) & \\
\hline Obese $(>=30)$ & $54(15)$ & $27(22.1)$ & $81(16.8)$ & & $63(16.3)$ & $20(19.6)$ & $83(17)$ & \\
\hline \multicolumn{9}{|c|}{ General Health condition from their own perspective } \\
\hline Excellent/Very good & $280(76.7)$ & $68(55.7)$ & $348(71.5)$ & $<0.001$ & $297(76.2)$ & $55(53.4)$ & $352(71.4)$ & $<0.001$ \\
\hline Good & $76(20.8)$ & $46(37.7)$ & 122(25) & & $86(22.1)$ & $38(36.9)$ & 124(25.2) & \\
\hline Fair/Poor & $9(2.5)$ & $8(6.6)$ & $17(3.5)$ & & $7(1.8)$ & $10(9.7)$ & 17(34.4) & \\
\hline \multicolumn{9}{|c|}{ Ever been in a violent relationship with partner } \\
\hline Yes & $22(6.1 \%)$ & $30(71.4)$ & $52(11)$ & $<0.001$ & $29(7.5)$ & $23(23)$ & $52(10.9)$ & $<0.001$ \\
\hline No & $337(93.1)$ & $85(25.2)$ & $422(89)$ & & $352(91.2)$ & $75(75)$ & $427(89.1)$ & \\
\hline \multicolumn{9}{|l|}{ Current tobacco smoking } \\
\hline Yes & $13(3.6)$ & $9(7.4)$ & $22(4.5)$ & 0.079 & $16(4.1)$ & $6(5.8)$ & $22(4.5)$ & 0.450 \\
\hline No & $352(96.4)$ & $113(92.6)$ & $465(95.5)$ & & $374(95.9)$ & $97(94.2)$ & $471(95.5)$ & \\
\hline \multicolumn{9}{|l|}{ Alcohol use } \\
\hline Low/High risk drinker & $261(71.7)$ & $79(65.3)$ & $340(70)$ & 0.182 & $276(71)$ & $68(66.7)$ & $344(70)$ & 0.400 \\
\hline Non-drinker & $103(28.3)$ & $42(34.7)$ & 145(30) & & $113(29)$ & $34(33.3)$ & 147(30) & \\
\hline \multicolumn{9}{|l|}{ Ever used illicit drugs } \\
\hline Yes & $228(65.2)$ & $88(72.1)$ & $316(65)$ & 0.053 & $244(62.6)$ & $74(71.8)$ & $318(64.5)$ & 0.081 \\
\hline No & $137(37.5)$ & $34(27.9)$ & $171(35)$ & & $146(37.4)$ & $29(28.2)$ & $175(35.5)$ & \\
\hline \multicolumn{9}{|l|}{ Current Anxiety (GAD) } \\
\hline Yes $(>=6)$ & $36(9.9)$ & $67(54.9)$ & $103(21.2)$ & $<0.001$ & - & - & & \\
\hline No $(<6)$ & $328(90.1)$ & $55(45.1)$ & $383(78.8)$ & & - & - & & \\
\hline Current Depression (CES-D 10) & & & & & & & & \\
\hline Yes $(>=8)$ & - & - & & & $55(14.3)$ & $67(65)$ & $122(25)$ & $<0.001$ \\
\hline $\mathrm{No}(<8)$ & - & - & & & $329(85.7)$ & $36(35)$ & $365(75)$ & \\
\hline History depression in the past $3 y$ & ars (Previou & ntal health) & & & & & & \\
\hline Yes & $27(7.5)$ & $30(25)$ & 57(11.9) & $<0.001$ & $31(8.1)$ & $27(26.5)$ & $58(12)$ & $<0.001$ \\
\hline
\end{tabular}


Table 2 (continued)

\begin{tabular}{|c|c|c|c|c|c|c|c|c|}
\hline \multirow{3}{*}{ Variables } & \multicolumn{2}{|c|}{ Antenatal Depression } & \multirow{3}{*}{$\begin{array}{l}\text { Total } \\
(n=493) \\
n(\%)\end{array}$} & \multirow[t]{3}{*}{ p-value } & \multicolumn{2}{|c|}{ Antenatal Anxiety } & \multirow{3}{*}{$\begin{array}{l}\begin{array}{l}\text { Total } \\
(n=493)\end{array} \\
n(\%)\end{array}$} & \multirow[t]{3}{*}{ p-value } \\
\hline & $\begin{array}{l}\text { No } \\
(n=365)\end{array}$ & $\begin{array}{l}\text { Yes } \\
(n=122)\end{array}$ & & & \multirow{2}{*}{$\begin{array}{l}\text { No } \\
(n=390) \\
n(\%)\end{array}$} & \multirow{2}{*}{$\begin{array}{l}\text { Yes } \\
(n=103) \\
n(\%)\end{array}$} & & \\
\hline & n (\%) & n (\%) & & & & & & \\
\hline No & $332(92.5)$ & $90(75)$ & $422(88.1)$ & & $352(91.9)$ & $75(73.2)$ & $427(88)$ & \\
\hline \multicolumn{9}{|c|}{ History anxiety in the past 3 years (Previous Mental health) } \\
\hline Yes & $14(3.9)$ & $18(15)$ & $32(6.7)$ & $<0.001$ & $19(5)$ & $13(12.7)$ & $58(12)$ & 0.005 \\
\hline No & $345(96.1)$ & $102(85)$ & $447(93.3)$ & & $364(85)$ & $89(87.3)$ & $427(88)$ & \\
\hline \multicolumn{9}{|c|}{ Mean Stress score } \\
\hline$\leq 0.27$ & $86(23.6)$ & $2(1.7)$ & $88(18.2)$ & $<0.001$ & 84 (21.6) & $4(3.9)$ & $88(18)$ & $<0.001$ \\
\hline $0.28-0.56$ & $162(44.5)$ & $29(24)$ & 191(39.4) & & $174(44.8)$ & 21 (20.6) & 195(39.8) & \\
\hline $0.57-0.82$ & $68(18.7)$ & 31 (25.6) & $99(20.4)$ & & $73(18.8)$ & $26(25.5)$ & $99(20.2)$ & \\
\hline $0.83-4$ & $48(13.2)$ & $59(48.8)$ & $107(22)$ & & $57(14.7)$ & $51(50)$ & $108(22)$ & \\
\hline Mean ( $\pm S D)$ & $0.61( \pm 0.43)$ & & & & & & & \\
\hline \multicolumn{9}{|c|}{ LOT-R Optimism } \\
\hline 0-14.99 & $59(16.2)$ & $57(47.1)$ & $116(23.9)$ & $<0.001$ & $72(18.5)$ & 45 (43.7) & 117(23.8) & $<0.001$ \\
\hline $15-17.99$ & $88(24.1)$ & $28(23.1)$ & $116(23.9)$ & & $96(24.7)$ & $23(22.3)$ & $119(24.2)$ & \\
\hline 18-18.99 & $81(22.2)$ & $20(16.5)$ & 101(20.8) & & $86(22.1)$ & $17(16.5)$ & 103(20.9) & \\
\hline $19-24$ & $137(37.5)$ & 16(13.7) & 153(31.5) & & $135(34.7)$ & 18(17.5) & 153(31.1) & \\
\hline Mean $( \pm S D)$ & $16.85( \pm 4.05)$ & & & & & & & \\
\hline
\end{tabular}

Note: $\mathrm{p}$-value was based on chi-square test and t-test statistics, Abbreviation: C/S: Cesarean Section

Table 3 Multiple logistic regression model, showing the association between social support and antenatal depressive symptoms among Australian women, after adjusting potential confounders $(n=493)$

\begin{tabular}{|c|c|c|c|c|}
\hline \multirow[t]{3}{*}{ Variables } & \multicolumn{2}{|c|}{ Antenatal Depression } & \multirow[t]{3}{*}{ AOR $(95 \% \mathrm{Cl})$} & \multirow[t]{3}{*}{ p-value } \\
\hline & $\begin{array}{l}\text { No } \\
(n=365)\end{array}$ & $\begin{array}{l}\text { Yes } \\
(n=122)\end{array}$ & & \\
\hline & n (\%) & n (\%) & & \\
\hline \multicolumn{5}{|c|}{ Medical Outcomes Study Social Support Index } \\
\hline \multicolumn{5}{|c|}{ Emotional/Informational support ${ }^{\dagger}$} \\
\hline High (All/Most of the time) & $358(98.1)$ & $90(73.8)$ & 1 & \\
\hline Low (Some/none/little of the time) & $7(1.9)$ & $32(26.2)$ & $4.75(1.45,15.66)$ & 0.010 \\
\hline \multicolumn{5}{|l|}{ 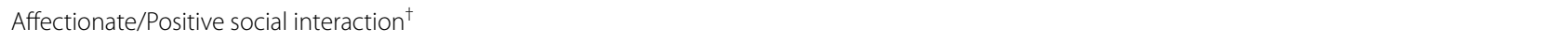 } \\
\hline High (All/Most of the time) & $361(98.9)$ & $101(83.5)$ & 1 & \\
\hline Low (Some/none/little of the time) & $4(1.1)$ & $20(16.5)$ & $1.65(0.38,8.12)$ & 0.53 \\
\hline \multicolumn{5}{|l|}{ Tangible Support ${ }^{\dagger}$} \\
\hline High (All/Most of the time) & $341(93.4)$ & 95(77.9) & 1 & \\
\hline Low (Some/none/little of the time) & $24(6.6)$ & $27(22.1)$ & $1.49(0.53,4.19)$ & 0.44 \\
\hline \multicolumn{5}{|l|}{ Overall social support ${ }^{*}$} \\
\hline High (All/Most of the time) & $356(97.5)$ & $97(79.5)$ & 1 & \\
\hline Low (Some/none/little of the time) & $9(2.5)$ & $25(20.5)$ & $3.26(1.05,10.10)$ & 0.040 \\
\hline
\end{tabular}

${ }^{\dagger}$ Model is adjusted for: marital status, age, GP use, BMI, general health condition from their own perspective, ever been in a violent relationship with partner, ever used illicit drug, current Tobacco smoking, Alcohol use, current anxiety symptoms, history of depression in the past 3 years, history of anxiety in the past 3 years, mean stress score, and optimism. Hosmer and Lemeshow Test (Chi-square $=4.6, \mathrm{df}=8, p=0.799$ )

$¥$ Model is adjusted for: marital status, age, GP use, BMl, general health condition from their own perspective, ever been in a violent relationship with partner, ever used illicit drug, current Tobacco smoking, Alcohol use, current anxiety symptoms, history of depression in the past 3 years, history of anxiety in the past 3 years, mean stress score, and optimism. Hosmer and Lemeshow Test (Chi-square $=1.839, \mathrm{df}=8, p=0.986$ ) 
Table 4 Multiple logistic regression model, showing the association between social support and antenatal anxiety symptoms among Australian women, after adjusting potential confounders $(n=493)$

\begin{tabular}{|c|c|c|c|c|}
\hline \multirow[t]{3}{*}{ Variables } & \multicolumn{2}{|c|}{ Antenatal Anxiety } & \multirow[t]{3}{*}{ AOR $(95 \% \mathrm{Cl})$} & \multirow[t]{3}{*}{ p-value } \\
\hline & \multirow{2}{*}{$\begin{array}{l}\text { No } \\
(n=390) \\
n(\%)\end{array}$} & \multirow{2}{*}{$\begin{array}{l}\text { Yes } \\
(n=103) \\
n(\%)\end{array}$} & & \\
\hline & & & & \\
\hline \multicolumn{5}{|c|}{ Medical Outcomes Study Social Support Index } \\
\hline \multicolumn{5}{|c|}{ Emotional/Informational support ${ }^{\dagger}$} \\
\hline High (All/Most of the time) & $374(96.1)$ & $79(76.7)$ & 1 & \\
\hline Low (Some/none/little of the time) & $15(3.9)$ & $24(23.3)$ & $1.12(0.36,3.47)$ & 0.840 \\
\hline \multicolumn{5}{|l|}{ 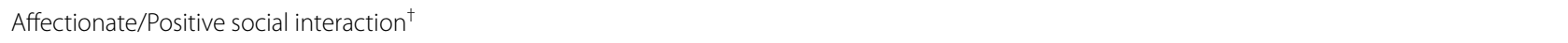 } \\
\hline High (All/Most of the time) & $384(98.7)$ & $83(81.4)$ & 1 & \\
\hline Low (Some/none/little of the time) & $5(1.3)$ & 19 (18.6) & $7.43(1.75,31.55)$ & 0.006 \\
\hline \multicolumn{5}{|l|}{ Tangible Support $^{\dagger}$} \\
\hline High (All/Most of the time) & $356(91.8)$ & 83(80.6) & 1 & \\
\hline Low (Some/none/little of the time) & $32(8.2)$ & 20(19.4) & $0.88(0.32,2.45)$ & 0.811 \\
\hline \multicolumn{5}{|l|}{ Overall social support ${ }^{*}$} \\
\hline High (All/Most of the time) & 375(96.4) & $82(79.6)$ & 1 & \\
\hline Low (Some/none/little of the time) & 14(3.6) & $21(20.4)$ & $2.55(0.92,7.06)$ & 0.071 \\
\hline \multicolumn{5}{|c|}{$\begin{array}{l}{ }^{\dagger} \text { Model is adjusted for: marital status, ability to manage on available income, GP use, general health condition from their own perspective, ever been in a violent } \\
\text { relationship with partner, ever used illicit drug, preterm history, current depressive symptoms, history of depression in the past } 3 \text { years, history of anxiety in the past } \\
\text { 3years, mean stress score, and optimism. Hosmer and Lemeshow Test (Chi-square }=5.627, \mathrm{df}=8, p=0.689 \text { ) }\end{array}$} \\
\hline
\end{tabular}

and mental health problems, including depressive and anxiety symptoms, during pregnancy among Australian women.

After adjusting for potential confounders, in the current study, low emotional/informational support was found to have a significant association with a higher odds of antenatal depressive symptoms. Likewise, the odds of depressive symptoms was three times higher among pregnant women who reported low social support (overall support) compared with their counterpart. Pregnant women with low emotional support/informational support may not have someone to confide in, obtain important information/advice from, or to help reduce the negative emotions associated with a distressing situation, and as a result, they might be exposed to stress and may later develop depression [69]. The positive relationship between low social support (overall support) and antenatal depressive symptoms was supported by other studies conducted in Australia and internationally. A facilitybased cross-sectional study conducted in Turkey among pregnant women $(n=772)$ indicated that emotional and instrumental support, from the mother-in-law and general support from the husband had an inverse relation with antenatal depression [70]. Also, a study conducted in Australia on pregnant women $(n=367)$ emphasized that overall social support was negatively associated with antenatal depression [11]. Similarly, previous studies conducted in Ethiopia [71], Sweden [72], USA [73], Finland [74], and China [75] reported pregnant women who reported low social support were more likely to be depressed. However, none of the above-mentioned studies examined the relationship between specific domains of social support and antenatal depressive symptoms. On the contrary, a facility-based cross-sectional study conducted in Jordan $(n=218)$ reported that social support during pregnancy has no association with antenatal depression [76]. The possible reasons for this conflicting finding might be due to the variation in demographic characteristics of participants, and tools used to assess social support and adjustment of confounders. In the study conducted in Jordan, participants were those with age $\geq 18$ years and used the Duke Social Support and Stress Scale (DUSOCS) (12 items) which examines the amount of overall social support and number of supportive people [77]. However, in our study participants were between the age of 34-39years old, used MOS-SSS (19 items) scale [56] to assess overall and domains of social support such as perceived emotional/informational support, tangible support, affectionate support, and positive social interaction.

Our study showed that pregnant women who reported low affectionate support/positive social interaction had a 
higher odds of anxiety symptoms compared to pregnant women who reported high affectionate support/positive social interaction. Pregnant women with low affectionate support/positive social interaction are less satisfied with family and poor in interacting with the social environment, and as a result, they might be exposed to loneliness, become less in emotional and stress coping ability and later become more anxious $[69,78]$. However, we found insufficient statistical evidence for an association between low social support (overall support) and antenatal anxiety symptoms. Similar findings were reported from facility-based studies conducted in Greece $(n=165)$ [79] and Canada $(n=5271)$ [80], which stated low social support had no significant association with antenatal anxiety. On the contrary, studies conducted in the US [81], China [75, 82], and Germany [83], which all reported that low social support (overall support) had a significant association with antenatal anxiety symptoms. The possible reasons for this discrepancy might be due to the difference in demographic characteristics of participants, the instrument used to assess social support and adjustment of potential confounders. For instance, the study conducted in the US [81] used Turner Support Scale to assess only partner support given for pregnant women and adjusted only for confounders like maternal race/ethnicity, age, parity, education, pre-pregnancy BMI, and household income. However, our study used MOS-SSS (19 items) scale [56] to assess the overall and specific domains of social support (i.e., emotional support/informational support, affectionate support/positive interaction and tangible support) and adjusted for potential confounders from socio-demographic, behavioural and psychological characteristics of participants.

Almost 1 in 4 pregnant women in our study met the screening criteria for depressive symptoms. The finding is supported by several other studies conducted worldwide such as in Jamaica (25\%) [84], Nigeria (24.9\%) [85], Brazil (24.3\%) [86], Vietnam (22.4\%) [87] and South Africa (22\%) [88]. However our finding is higher than a previous Australian national report (6\%) [9] and other studies conducted in Australia, ranging from 7 to $17 \%$ [10, 11]. One possible reason that may account for the inconsistency regarding the prevalence of depressive symptoms during pregnancy between the current study and other studies conducted in Australia might be due to the use of instruments used to examine depression. That is, all studies conducted in Australia used EPDS (10 items) with a total score of $\geq 13$ considered a flag for possible depressive symptoms [89], however, the current study used the CES-D-10 screening tool, with a score $\geq 10$ suggestive of possible depressive symptoms [48].

Our study found that 1 in 5 pregnant women screened positive for anxiety symptoms. A comparable estimate of antenatal anxiety symptoms was reported from a study conducted in Canada (23\%) [23], and a global level systematic review and meta-analysis, $18.2 \%$ (10 studies) for the 1st trimester and 19.1\% (17 studies) for the 2nd trimester) [13]. However, a facility-based longitudinal cohort study conducted in Melbourne, Australia, reported a higher prevalence of antenatal anxiety (27.7\%) [11]. The possible reason for the observed difference might be due to variation in demographic characteristics of participants, participant recruitment method, and instrument employed to screen antenatal anxiety symptoms. For example, in the study conducted in Melbourne, Australia, participants were between the age of $17-45$ years, recruited participants from antenatal clinic attendees, followed longitudinal study design and used the Beck anxiety inventory scale (BAI-21 items) (a selfreported scale used to examine the level of physical and cognitive anxiety symptoms in the past week) [90] to screen antenatal anxiety, while in our study, participants were between the age of 34-39 years, recruited participants from a community, and used GADS (a score $\geq 6$ suggests the presence of anxiety symptoms) scale to screen antenatal anxiety symptoms.

Our study has some limitations that need to be considered when making inferences from our findings. First, the study relied on self-reported data from participants, which has the potential for recall bias to be introduced. Second, our findings are limited to pregnant women within the age range of 34-39years and as such, our findings may not be generalizable to younger pregnant women. Third, as the data analysis was cross-sectional we cannot confirm the necessary time-based direction of events. Specifically, the presence of reverse causation between low social support and depressive and/or anxiety symptoms cannot be identified. Finally, the sample size of our study may have resulted in reduced statistical power and inflated effect size estimation. However, these limitations are countered by the fact that the study analyzed data collected from a nationally representative sample of pregnant women.

\section{Conclusion}

A considerable proportion of pregnant Australian women had depressive and anxiety symptoms, which poses serious health concerns. Early screening of pregnant women for antenatal depressive and anxiety symptoms is important for the wellbeing of the mother and child. Low emotional/informational support and low affectionate support/positive social interaction have been identified as being significantly associated with antenatal depressive and anxiety symptoms respectively. As such we recommend that targeted screening of pregnant women for social support is important to prevent anxiety 
and/or depressive symptoms amongst pregnant women. Policy-makers and those working on maternity care need to consider the development of community-based social support programs to maintain the mental wellbeing of pregnant women. Finally, for future researchers, we recommend longitudinal studies with the view to examine the causative relationship between low social support and depressive and/or anxiety symptoms during pregnancy.

\begin{abstract}
Abbreviations
ALSWH: Australian Longitudinal Study on Women's Health; AOR: Adjusted Odds Ratio; BAl: Beck Anxiety Inventory; BMI: Body Mass Index; CESD-10: 10 item Center for Epidemiological Study Depression scale; C/S: Cesarean Section; DUSOCS: Duke Social Support and Stress Scale; EPDS: Edinburgh Postnatal Depression Scale; GADS: Goldberg Anxiety Depression Scale; GP: General Practitioner; LMICs: Low and Middle-Income Countries; LOT-R: Life Orientation Test-Revised; MOS-SSS-19: 19 item Medical Outcome Study Social Support Scale; STAl: State-Trait Anxiety Inventory; WHO: World Health Organization.
\end{abstract}

\section{Supplementary Information}

The online version contains supplementary material available at https://doi. org/10.1186/s12884-021-04188-4.

Additional file 1. STROBE Statement—Checklist of items included in reports.

Additional file 2. Sensitivity analysis (E-values) for the association between low social support and the risk of antenatal depressive symptoms for the final adjusted model.

Additional file 3. Sensitivity analysis (E-values) for the association between low social support and the risk of antenatal anxiety symptoms for the final adjusted model.

\section{Acknowledgements}

The research on which this paper is based was conducted as part of the Australian Longitudinal Study on Women's Health, the University of Newcastle and the University of Queensland. We would like to acknowledge the Australian Government Department of Health and Ageing for funding and to the women who provided the survey data.

\section{Authors' contributions}

$A B$ and $D S$ conceived the study, planned the study design and performed the analyses. AB performed the report write-up and drafted the manuscript. DS, JA \&WP contributed to the analysis, reviewing draft document and manuscript. All authors read and approved the final manuscript.

\section{Funding}

The ALSWH is funded by the Australian Government Department of Health and Ageing. The funding source had no role in the design, data collection, analysis, manuscript write-up; or in the decision to submit the manuscript for publication.

\section{Availability of data and materials}

After request, all analyzed data will be available from the Australian Longitudinal Study on Women's Health (ALSWH). https://www.alswh.org.au/.

\section{Declarations}

Ethics approval and consent to participate

The ALSWH has been granted ethics clearance by the human research Ethics committee of the University of Newcastle (\#H-076-0795) and the University of Queensland (\#2004000224). Study participants were involved voluntarily and provided written informed consent. The confidentiality of study participants' information is firmly monitored by ALSWH staff. Approval letter for the current study was obtained from the Human Research Ethics Committee of the University of Technology Sydney (ETH20-5306).

\section{Consent for publication}

Not applicable.

\section{Competing interests}

The authors declare they have no competing interests.

\section{Author details}

${ }^{1}$ Hawassa University, College of Medicine and Health Sciences, School of Nursing, Hawassa, Ethiopia. ${ }^{2}$ Australian Centre for Public and Population Health Research, School of Public Health, Faculty of Health, University of Technology Sydney, Ultimo, NSW, Australia.

Received: 15 June 2021 Accepted: 12 October 2021

Published online: 22 October 2021

\section{References}

1. Smith MV, Shao L, Howell H, Lin H, Yonkers KA. Perinatal depression and birth outcomes in a healthy start project. Matern Child Health J. 2011:15:401-9.

2. Wadhwa PD, Glynn L, Hobel CJ, Garite TJ, Porto M, Chicz-DeMet A, et al. Behavioral perinatology: biobehavioral processes in human fetal development. Regul Pept. 2002;108:149-57.

3. Dunkel Schetter C. Psychological science on pregnancy: stress processes, biopsychosocial models, and emerging research issues. Annu Rev Psychol. 2011;62:531-58.

4. Rich-Edwards JW, Kleinman K, Abrams A, Harlow BL, McLaughlin TJ, Joffe $\mathrm{H}$, et al. Sociodemographic predictors of antenatal and postpartum depressive symptoms among women in a medical group practice. J Epidemiol Community Health. 2006;60:221-7.

5. Kastrup MC, Ramos AB. Global mental health. Dan Med Bull. 2007;54:42-3.

6. Bennett HA, Einarson A, Taddio A, Koren G, Einarson TR. Prevalence of depression during pregnancy: a systematic review. Obstet Gynecol. 2004; 103:698-709.

7. Gelaye B, Rondon MB, Araya R, Williams MA. Epidemiology of maternal depression, risk factors, and child outcomes in low-income and middleincome countries. Lancet Psychiatry. 2016;3:973-82.

8. Ogbo FA, Eastwood J, Hendry A, Jalaludin B, Agho KE, Barnett B, et al. Determinants of antenatal depression and postnatal depression in Australia. BMC Psychiatry. 2018;18:49.

9. Buist A, Bilszta J, Milgrom J, Condon J, Speelman C, Hayes B, et al. The beyondblue National Postnatal Depression Program, Prevention and Early Intervention 2001-2005, Final Report. Hawthorn West, Vic: Beyondblue: The National Depression Initiative; 2006.

10. Eastwood J, Ogbo F, Hendry A, Noble J, Page A. Early years research group (EYRG). The Impact of Antenatal Depression on Perinatal Outcomes in Australian Women. PLoS One. 2017;12:e0169907.

11. Leigh B, Milgrom J. Risk factors for antenatal depression, postnatal depression and parenting stress. BMC Psychiatry. 2008;8:24.

12. Huizink AC, Mulder EJ, de Medina PGR, Visser GH, Buitelaar JK. Is pregnancy anxiety a distinctive syndrome? Early Hum Dev. 2004;79:81-91.

13. Dennis C-L, Falah-Hassani K, Shiri R. Prevalence of antenatal and postnatal anxiety: systematic review and meta-analysis. Br J Psychiatry. 2017:210:315-23.

14. Serçekuş P, Okumuş H. Fears associated with childbirth among nulliparous women in Turkey. Midwifery. 2009;25:155-62.

15. Rico MAG, Rodríguez AJM, Díez SMU, Real MCM. Análisis de la relación entre riesgo gestacional y ansiedad materna. Progresos de Obstetricia y Ginecología. 2010;53:273-9.

16. Hernández-Martínez C, Val VA, Murphy M, Busquets PC, Sans JC. Relation between positive and negative maternal emotional states and obstetrical outcomes. Women \& health. 2011;51:124-35.

17. Nieminen K, Stephansson O, Ryding EL. Women's fear of childbirth and preference for cesarean section-a cross-sectional study at various stages of pregnancy in Sweden. Acta Obstet Gynecol Scand. 2009;88:807-13. 
18. Teixeira C, Figueiredo B, Conde A, Pacheco A, Costa R. Anxiety and depression during pregnancy in women and men. J Affect Disord. 2009;119:142-8.

19. Faisal-Cury A, Menezes PR. Prevalence of anxiety and depression during pregnancy in a private setting sample. Archives of women's mental health. 2007;10:25-32.

20. Gong X, Hao J, Tao F, Zhang J, Wang H, Xu R. Pregnancy loss and anxiety and depression during subsequent pregnancies: data from the C-ABC study. European Journal of Obstetrics \& Gynecology and Reproductive Biology. 2013;166:30-6.

21. Bogaerts AF, Devlieger R, Nuyts E, Witters I, Gyselaers W, Guelinckx I, et al. Anxiety and depressed mood in obese pregnant women: a prospective controlled cohort study. Obesity facts. 2013;6:152-64.

22. Woods-Giscombé CL, Lobel M, Crandell JL. The impact of miscarriage and parity on patterns of maternal distress in pregnancy. Research in nursing \& health. 2010;33:316-28.

23. Bayrampour H, McDonald S, Tough S. Risk factors of transient and persistent anxiety during pregnancy. Midwifery. 2015;31:582-9.

24. Agrati D, Browne D, Jonas W, Meaney M, Atkinson L, Steiner M, et al. Maternal anxiety from pregnancy to 2 years postpartum: transactional patterns of maternal early adversity and child temperament. Archives of women's mental health. 2015;18:693-705.

25. Buist A, Gotman N, Yonkers KA. Generalized anxiety disorder: course and risk factors in pregnancy. J Affect Disord. 2011;131:277-83.

26. Byatt N, Hicks-Courant K, Davidson A, Levesque R, Mick E, Allison J, et al. Depression and anxiety among high-risk obstetric inpatients. Gen Hosp Psychiatry. 2014;36:644-9.

27. Fadzil A, Balakrishnan K, Razali R, Sidi H, Malapan T, Japaraj RP, et al. Risk factors for depression and anxiety among pregnant women in $\mathrm{H}$ ospital $\mathrm{T}$ uanku B ainun, I poh, M alaysia. Asia Pac Psychiatry. 2013;5:7-13.

28. Arch JJ. Pregnancy-specific anxiety: which women are highest and what are the alcohol-related risks? Compr Psychiatry. 2013;54:217-28.

29. Rubertsson C, Hellström J, Cross M, Sydsjö G. Anxiety in early pregnancy: prevalence and contributing factors. Archives of women's mental health. 2014;17:221-8.

30. van Heyningen T, Honikman S, Myer L, Onah MN, Field S, Tomlinson M. Prevalence and predictors of anxiety disorders amongst low-income pregnant women in urban South Africa: a cross-sectional study. Arch Womens Ment Health. 2017;20:765-75.

31. Biaggi A, Conroy S, Pawlby S, Pariante CM. Identifying the women at risk of antenatal anxiety and depression: a systematic review. J Affect Disord. 2016;191:62-77.

32. Edwards B, Galletly C, Semmler-Booth T, Dekker G. Antenatal psychosocial risk factors and depression among women living in socioeconomically disadvantaged suburbs in Adelaide, South Australia. Australian \& New Zealand Journal of Psychiatry. 2008;42:45-50.

33. Bisetegn TA, Mihretie G, Muche T. Prevalence and predictors of depression among pregnant women in Debretabor town, Northwest Ethiopia. PLoS One. 2016;11:e0161108.

34. Biratu A, Haile D. Prevalence of antenatal depression and associated factors among pregnant women in Addis Ababa, Ethiopia: a cross-sectional study. Reprod Health. 2015;12:99.

35. Orr ST, Miller CA. Maternal depressive symptoms and the risk of poor pregnancy outcome: review of the literature and preliminary findings. Epidemiol Rev. 1995;17:165-71.

36. Kurki T, Hiilesmaa V, Raitasalo R, Mattila H, Ylikorkala O. Depression and anxiety in early pregnancy and risk for preeclampsia. Obstet Gynecol. 2000:95:487-90.

37. Freeman MP. Perinatal psychiatry: risk factors, treatment data, and specific challenges for clinical researchers. The Journal of clinical psychiatry. 2008;69:633-4.

38. Hollins K. Consequences of antenatal mental health problems for child health and development. Curr Opin Obstet Gynecol. 2007;19:568-72.

39. Heron J, O'Connor TG, Evans J, Golding J, Glover V, Team AS. The course of anxiety and depression through pregnancy and the postpartum in a community sample. J Affect Disord. 2004:80:65-73.

40. Hart S, Field T, del Valle C, Pelaez-Nogueras M. Depressed mothers'interactions with their one-year-old infants. Infant Behav Dev. 1998;21:519-25.

41. Figueiredo B, Costa R, Pacheco A, Pais A. Mother-to-infant emotional involvement at birth. Matern Child Health J. 2009;13:539-49.
42. Da Costa D, Larouche J, Dritsa M, Brender W. Psychosocial correlates of prepartum and postpartum depressed mood. J Affect Disord. 2000:59:31-40.

43. Cohen MM, Ansara D, Schei B, Stuckless N, Stewart DE. Posttraumatic stress disorder after pregnancy, labor, and delivery. Journal of Women's Health. 2004;13:315-24.

44. Cohen S, Underwood LG, Gottlieb BH. Social support measurement and intervention: a guide for health and social scientists: Oxford University Press; 2000.

45. Brown WJ, Bryson L, Byles JE, Dobson AJ, Lee C, Mishra G, et al. Women's health Australia: recruitment for a national longitudinal cohort study. Women \& health. 1999;28:23-40.

46. Loxton D, Tooth L, Harris ML, Forder PM, Dobson A, Powers J, et al. Cohort profile: the Australian longitudinal study on Women's health (ALSWH) 1989-95 cohort. International journal of epidemiology. 2018:47:391-392e.

47. Lee C, Dobson AJ, Brown WJ, Bryson L, Byles J, Warner-Smith P, et al. Cohort profile: the Australian longitudinal study on women's health. Int J Epidemiol. 2005;34:987-91.

48. Andresen EM, Malmgren JA, Carter WB, Patrick DL. Screening for depression in well older adults: evaluation of a short form of the CES-D (Center for Epidemiologic Studies Depression Scale). Am J Prev Med. 1994;10:77-84

49. Canady RB, Stommel M, Holzman C. Measurement properties of the centers for epidemiological studies depression scale (CES-D) in a sample of African American and non-Hispanic white pregnant women. Jurs Meas. 2009;17:91-104.

50. Mosack V, Shore ER. Screening for depression among pregnant and postpartum women. J Community Health Nurs. 2006;23:37-47.

51. Marcus SM, Flynn HA, Blow FC, Barry KL. Depressive symptoms among pregnant women screened in obstetrics settings. J Women's Health. 2003;12:373-80.

52. Holzman C, Eyster J, Tiedje LB, Roman LA, Seagull E, Rahbar MH. A life course perspective on depressive symptoms in mid-pregnancy. Matern Child Health J. 2006:10:127.

53. Seto M, Cornelius MD, Goldschmidt L, Morimoto K, Day NL. Long-term effects of chronic depressive symptoms among low-income childrearing mothers. Matern Child Health J. 2005;9:263-71.

54. Goldberg D, Bridges K, Duncan-Jones P, Grayson D. Detecting anxiety and depression in general medical settings. Bmj. 1988:297:897-9.

55. Leach LS, Christensen H, Mackinnon A. Pregnancy and levels of depression and anxiety: a prospective cohort study of Australian women. Australian \& New Zealand Journal of Psychiatry. 2014;48:944-51.

56. Sherbourne CD, Stewart AL. The MOS social support survey. Soc SCi Med. 1991;32:705-14.

57. Russell A, Smith N. Medical outcomes study social support index: ALSWH data dictionary supplement. Newcastle, Australia: Australian Longitudinal Study on Women's Health; 2002.

58. Chojenta C, Loxton D, Lucke J. How do previous mental health, social support, and stressful life events contribute to postnatal depression in a representative sample of Australian women? J Midwifery Womens Health. 2012;57:145-50.

59. Department of Health and Aged Care (GISCA). Measuring remoteness: Accessibility/Remoteness Index of Australia (ARIA) Revised Ed. Canberra: Department of Health and Aged Care; 2001.

60. Bell S, Lee C. Development of the perceived stress questionnaire for young women. Psychology, Health \& Medicine. 2002;7:189-201.

61. Bell S, Lee C. Perceived stress revisited: the Women's health Australia project young cohort. Psychology, Health \& Medicine. 2003;8:343-53.

62. Bell S, Lee $C$. Does timing and sequencing of transitions to adulthood make a difference? Stress, smoking, and physical activity among young Australian women. International journal of behavioral medicine. 2006;13:265-74.

63. Brussen KA. The Australian Guidelines to Reduce Health Risks from Drinking Alcohol. Chisholm Health Ethics Bulletin. 2010;15(3):9-12.

64. WHO. Physical status: The use and interpretation of anthropometry WHO technical report series. 1995;854(9).

65. Hosmer DW, Lemeshow S. Applied logistic regression. New York: John Wiley \& Sons; 2000. 
66. Haneuse S, VanderWeele TJ, Arterburn D. Using the E-value to assess the potential effect of unmeasured confounding in observational studies. Jama. 2019;321:602-3.

67. VanderWeele TJ, Ding P. Sensitivity analysis in observational research: introducing the E-value. Ann Intern Med. 2017;167:268-74.

68. Linden A, Mathur MB, VanderWeele TJ. Conducting sensitivity analysis for unmeasured confounding in observational studies using E-values: the evalue package. Stata J. 2020;20:162-75.

69. Thoits PA. Social support as coping assistance. J Consult Clin Psychol. 1986;54:416.

70. Senturk V, Abas M, Berksun O, Stewart R. Social support and antenatal depression in extended and nuclear family environments in Turkey: a cross-sectional survey. BMC Psychiatry. 2011;11:48.

71. Dibaba Y, Fantahun M, Hindin MJ. The association of unwanted pregnancy and social support with depressive symptoms in pregnancy: evidence from rural southwestern Ethiopia. BMC pregnancy and childbirth. 2013;13:135.

72. Rubertsson C, Waldenström U, Wickberg B. Depressive mood in early pregnancy: prevalence and women at risk in a national Swedish sample. Journal of Reproductive \& Infant Psychology. 2003:21:113-23.

73. Spoozak L, Gotman N, Smith MV, Belanger K, Yonkers KA. Evaluation of a social support measure that may indicate risk of depression during pregnancy. J Affect Disord. 2009;114:216-23.

74. Pajulo M, Savonlahti E, Sourander A, Helenius H, Piha J. Antenatal depression, substance dependency and social support. J Affect Disord. 2001;65:9-17.

75. Tang X, Lu Z, Hu D, Zhong X. Influencing factors for prenatal stress, anxiety and depression in early pregnancy among women in Chongqing, China. J Affect Disord. 2019;253:292-302.

76. Abujilban SK, Abuidhail J, Al-Modallal H, Hamaideh S, Mosemli O. Predictors of antenatal depression among Jordanian pregnant women in their third trimester. Health Care Women Int. 2014;35:200-15.

77. Salameh T. Factors influencing postpartum depression among Jordanian women. Amman, Jordan: University of Jordan, Faculty of Nursing; 2006.

78. Alden LE, Mellings TM. Generalized social phobia and social judgments: the salience of self-and partner-information. Journal of Anxiety Disorders. 2004;18:143-57.

79. Gourounti K, Anagnostopoulos F, Lykeridou K. Coping strategies as psychological risk factor for antenatal anxiety, worries, and depression among Greek women. Arch Womens Ment Health. 2013;16:353-61.

80. Dunkel Schetter C, Niles AN, Guardino CM, Khaled M, Kramer MS. Demographic, medical, and psychosocial predictors of pregnancy anxiety. Paediatric \& Perinatal Epidemiology. 2016;30:421-9.
81. Cheng ER, Rifas-Shiman SL, Perkins ME, Rich-Edwards JW, Gillman MW, Wright $R$, et al. The influence of antenatal partner support on pregnancy outcomes. J Women's Health (Larchmt). 2016;25:672-9.

82. Gao L, Qu J, Wang AY. Anxiety, depression and social support in pregnant women with a history of recurrent miscarriage: a cross-sectional study. J Reprod Infant Psychol. 2020;38(5):497-508.

83. Martini J, Petzoldt J, Einsle F, Beesdo-Baum K, Hofler M, Wittchen HU. Risk factors and course patterns of anxiety and depressive disorders during pregnancy and after delivery: a prospective-longitudinal study. J Affect Disord. 2015;175:385-95.

84. Pottinger AM, Trotman-Edwards $\mathrm{H}$, Younger N. Detecting depression during pregnancy and associated lifestyle practices and concerns among women in a hospital-based obstetric clinic in Jamaica. Gen Hosp Psychiatry. 2009;31:254-61.

85. Thompson O, Ajayi I. Prevalence of Antenatal Depression and Associated Risk Factors among Pregnant Women Attending Antenatal Clinics in Abeokuta North Local Government Area, Nigeria. Depress Res Treat. 2016;2016:4518979. https://doi.org/10.1155/2016/4518979. Epub 2016 Aug 18.

86. Melo EF Jr, Cecatti JG, Pacagnella RC, Leite DF, Vulcani DE, Makuch MY The prevalence of perinatal depression and its associated factors in two different settings in Brazil. J Affect Disord. 2012;136:1204-8.

87. Fisher J, Tran T, Tran TD, Dwyer T, Nguyen T, Casey GJ, et al. Prevalence and risk factors for symptoms of common mental disorders in early and late pregnancy in Vietnamese women: a prospective population-based study. J Affect Disord. 2013;146:213-9.

88. van Heyningen T, Myer L, Onah M, Tomlinson M, Field S, Honikman S. Antenatal depression and adversity in urban South Africa. J Affect Disord. 2016:203:121-9.

89. Kaida A, Matthews LT, Ashaba S, Tsai AC, Kanters S, Robak M, et al. Depression during pregnancy and the postpartum among HIV-infected women on antiretroviral therapy in Uganda. Journal of acquired immune deficiency syndromes (1999). 2014;67:S179.

90. Beck AT, Epstein N, Brown G, Steer RA. An inventory for measuring clinical anxiety: psychometric properties. J Consult Clin Psychol. 1988;56:893.

\section{Publisher's Note}

Springer Nature remains neutral with regard to jurisdictional claims in published maps and institutional affiliations.
Ready to submit your research? Choose BMC and benefit from:

- fast, convenient online submission

- thorough peer review by experienced researchers in your field

- rapid publication on acceptance

- support for research data, including large and complex data types

- gold Open Access which fosters wider collaboration and increased citations

- maximum visibility for your research: over $100 \mathrm{M}$ website views per year

At BMC, research is always in progress.

Learn more biomedcentral.com/submissions 